EXTENDED REPORT

\title{
Effects of RWJ 67657, a p38 mitogen activated protein kinase (MAPK) inhibitor, on the production of inflammatory mediators by rheumatoid synovial fibroblasts
}

\author{
J Westra, P C Limburg, P de Boer, M H van Rijswijk
}

Ann Rheum Dis 2004;63:1453-1459. doi: 10.1136/ard.2003.013011

See end of article for authors' affiliations

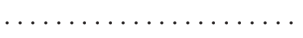

Correspondence to: Dr J Westra, Department of Rheumatology, University Hospital Groningen, $\mathrm{PO}$ Box $30.001,9700$ RB Groningen, Netherlands; j.westra@med.rug.nl

Accepted 24 January 2004

\begin{abstract}
Objective: To investigate the effect of the p38 mitogen activated protein kinase (MAPK) inhibitor RWJ 67657 on inflammatory mediator production by rheumatoid synovial fibroblasts (RSF).

Methods: RSF were pretreated with RWJ 67657 and stimulated with TNF $\alpha$ and/or IL-1 $\beta$. Protein levels and mRNA expression of MMP-1, MMP-3, TIMP-1, IL-6, and IL-8 were determined, as was mRNA expression of COX-2 and ADAMTS-4.

Results: MMP-3 production was significantly inhibited at $1 \mu$ M RJ 67657 and MMP-1 production at $10 \mu \mathrm{M}$, while TIMP- 1 production was not inhibited. Inhibition of IL-6 and IL-8 protein production was seen at $0.1 \mu \mathrm{M}$ RWJ 67657. Expression profiles of mRNA were in accordance with protein production. Inhibition of COX-2 mRNA expression occurred at $0.01 \mu \mathrm{M}$ RWJ 67657.

Conclusions: RWJ 67657 inhibits major proinflammatory mediator production in stimulated RSF at pharmacologically relevant concentrations. These findings could have important relevance for the treatment of rheumatoid arthritis.
\end{abstract}

$\mathrm{T}$ he pathogenesis of rheumatoid arthritis involves complex interrelations between $\mathrm{T}$ cells, macrophages, fibroblasts, and other immune cells. Growing evidence suggests that activated rheumatoid synovial fibroblasts (RSF) play a major role in both initiating and driving rheumatoid arthritis. ${ }^{1}$ In particular, RSF in the lining layer display numerous features of cellular activation which ultimately result in aggressive invasive behaviour. These cells can attach to the articular cartilage and invade the extracellular matrix. Furthermore, RSF are important producers of inflammatory mediators such as cytokines and matrix-metalloproteinases (MMP). Many of these mediators are regulated by mitogen activated protein kinase (MAPK) pathways and downstream transcription factors. $^{2}$ At least three subgroups of MAPK have been identified. These are the extracellular signal regulated kinases (ERK), the c-Jun $\mathrm{N}$-terminal or stress activated protein kinases (JNK/SAPK), and the p38 MAPK. ${ }^{3}$ In general ERK are activated by growth factors and hormones, whereas both JNK and p38 MAPK are activated by environmental stress and inflammatory cytokines. ${ }^{4}$

The involvement of p38 MAPK in the production of inflammatory mediators by fibroblasts has been reported in recent years. The role of p38 MAPK in relation to interleukin-6 (IL-6) and interleukin-8 (IL-8) production has been established in RSF. ${ }^{5}$ Also, involvement of p38 MAPK in MMP production has been demonstrated in dermal ${ }^{6}$ and gingival fibroblasts. ${ }^{7}$ Another matrix degrading enzyme, aggrecanase-1 or ADAMTS-4 (a disintegrin and metalloproteinase with thrombospondin motif), induced by cytokines in RSF, is important in cartilage degradation in rheumatoid arthritis. ${ }^{8}$ However, its signal transduction pathways are not known at the moment.

Prostaglandins have also been described as being under the influence of p38 MAPK. ${ }^{9}$ This has been confirmed in a study in which it was reported that glucocorticoids destabilise cyclo-oxygenase-2 (COX-2) mRNA by inhibiting the p38 MAPK route. ${ }^{10}$

Interest in protein kinases as drug targets has increased in the recent years; in particular, p38 MAPK inhibitors have been developed ${ }^{11-13}$ because p38 plays an important role as a major signal transducer responding to cellular stress stimuli such as cytokines. Because the production of interleukin-l (IL-1) and tumour necrosis factor $\alpha(\mathrm{TNF} \alpha)$ is influenced by p38 MAPK, p38 MAPK inhibitors are expected to inhibit not only the production of these principal proinflammatory cytokines but also their subsequent actions, leading to interruption of the vicious cycle that often occurs in inflammatory diseases. The use of p38 MAPK inhibitors could therefore provide an important advantage in treatment.

The p38 MAPK inhibitor RWJ 67657 (4-[4-(4-fluorophenyl)-1- (3-phenylpropyl) - 5 - (4-pyridinyl)-1H-imidazol-2-yl]3-butyn-1-ol) has been shown to inhibit the release of TNF $\alpha$ from lipopolysaccharide treated human peripheral blood mononuclear cells, with an $\mathrm{IC}_{50}$ of $3 \mathrm{nM}$, as well as inhibiting the release of TNF $\alpha$ from peripheral blood mononuclear cells treated with the super antigen staphylococcal enterotoxin B. ${ }^{14}$ This compound was approximately 10 -fold more potent than the reference standard p38 MAPK inhibitor SB 203580 in all p38 dependent in vitro systems tested. RWJ 67657 specifically inhibited the enzymatic activity of recombinant p38 $\alpha$ and $\beta$, but not $\gamma$ and $\delta$, in vitro, and had no significant activity against a variety of other kinases. ${ }^{14}$ Furthermore it was reported that this compound suppressed clinical and cytokine responses to endotoxin in healthy human volunteers. ${ }^{15}$ Recently a study was published on the pharmacokinetics and pharmacodynamics of RWJ 67657 in humans. ${ }^{16}$ This study showed acceptable safety and pharmacokinetic characteristics, warranting further investigation in a repeat-dose setting.

In the present study we investigated the effects of RWJ 67657 on the release of proinflammatory mediators produced

Abbreviations: ADAMTS, a disintegrin and metalloprotease with thrombospondin-1 motif; COX-2, cyclo-oxygenase-2; JNK, c-Jun Nterminal protein kinase; ERK, extracellular signal regulated kinase; IL, interleukin; MAPK, mitogen activated protein kinase; MMP, matrixmetalloproteinase; RSF, rheumatoid synovial fibroblast; SAPK, stress activated protein kinases; TIMP-1, tissue inhibitor of matrixmetalloproteinases; TNF, tumour necrosis factor 
by RSF, after stimulation with IL- $1 \beta$ or TNF $\alpha$ or both. Collagenase-1 (MMP-1), stromelysin-1 (MMP-3), and the tissue inhibitor of matrix-metalloproteinases (TIMP-1) were studied at both protein and mRNA expression level. The same was done for IL-6 and IL-8. In addition we looked at the effects on mRNA expression levels of aggrecanase-1 (ADAMTS-4) and COX-2.

\section{METHODS}

\section{Reagents}

RWJ 67657 was provided by Johnson and Johnson (RW Johnson Pharmaceutical Research Institute, Raritan, New Jersey, USA). Recombinant human IL- $1 \beta$ and recombinant human TNF $\alpha$ were purchased from R\&D Systems (Minneapolis, Minnesota, USA). Fetal calf serum (FCS) and Dulbecco's modified Eagle medium (DMEM) were obtained from Biowhittaker (Verviers, Belgium). Anti-CD14 antibodies were from IQP (Groningen, Netherlands) and anti-fibroblast antibodies (clone 5B5) from Dako (Glostrup, Denmark). All reagents for RNA isolation and reverse transcriptase reaction were obtained from Invitrogen, Life Technologies (Gaithersburg, Maryland, USA). Reagents for real time reverse transcriptase polymerase chain reaction (RT-PCR) were obtained from Applied Biosystems (Foster City, California, USA). Specific antibodies to p38 MAPK, phospho-p38 MAPK, and phospho-MAPKAPK-2 were purchased from Cell Signalling Technologies (Beverly, Massachusetts, USA)

\section{Isolation and culture of rheumatoid synovial} fibroblasts

Synovial fibroblasts were isolated from synovium from eight patients with rheumatoid arthritis who underwent total joint replacement. Synovium was minced and digested with

Stimulus:

$\mathrm{TNF} \alpha$

IL-1 $\beta$
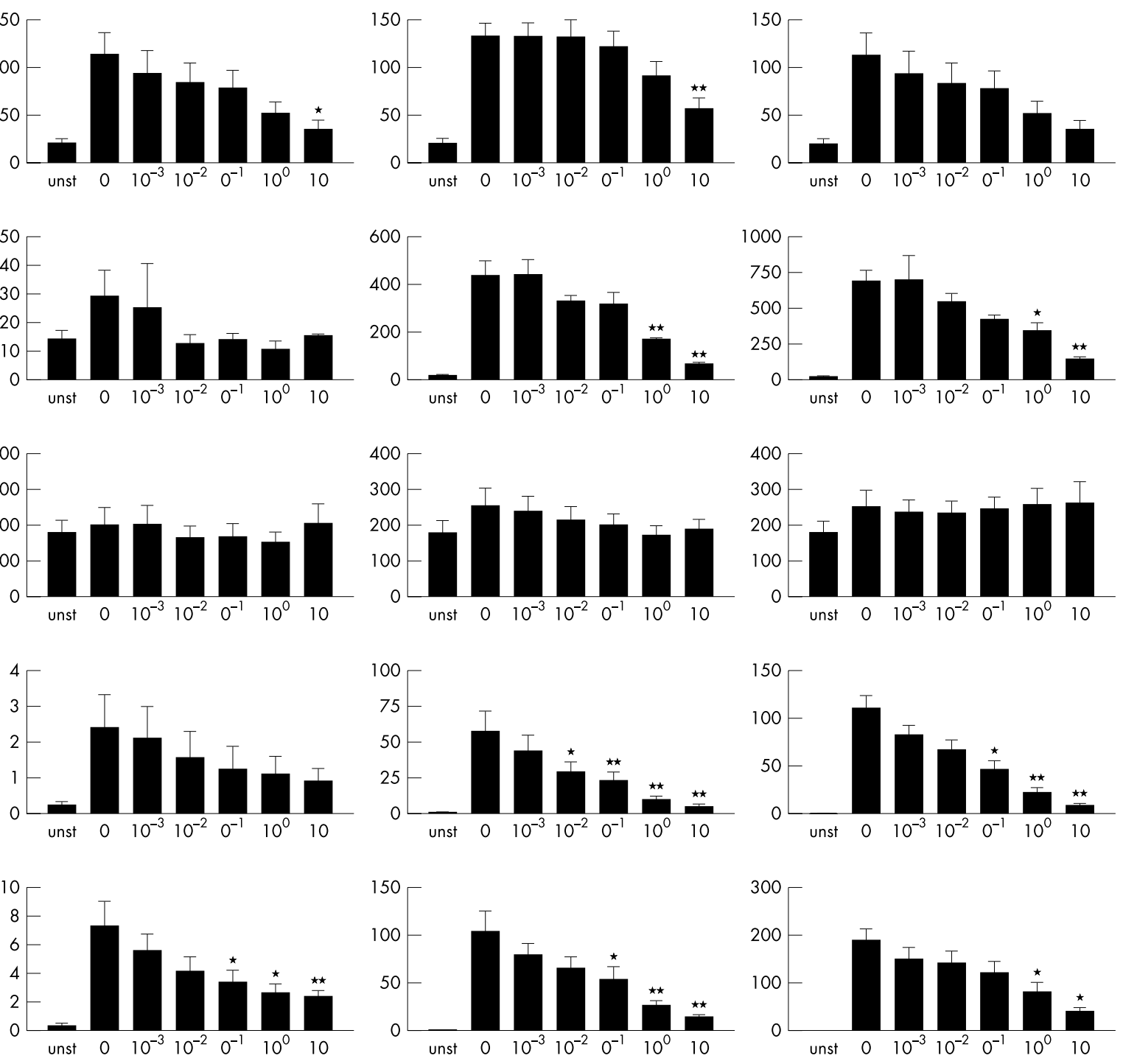

$\mu M$ RWJ 67657

Figure 1 Protein production of MMP-1, MMP-3, TIMP-1, IL-6, and IL-8 by rheumatoid synovial fibroblasts $(n=5)$. Cells were stimulated with TNF $\alpha$ and/or IL-1 $\beta$ for 48 hours and pretreated with a concentration range of RWJ $67657(t=-1 \mathrm{~h})$. Protein production was measured in supernatants by ELISA and expressed in $\mathrm{ng} / \mathrm{ml}$. unst, unstimulated; 0-10, concentration RWJ 67657 added. Bars show mean and SEM. ${ }^{*} \mathrm{p}<0.05,{ }^{* *} \mathrm{p}<0.001$, Dunnett's post test, tested against the stimulated control. IL, interleukin; MMP, matrix-metalloproteinase; TIMP-1, tissue inhibitor of matrixmetalloproteinases; TNF, tumour necrosis factor. 
$1 \mathrm{mg} / \mathrm{ml}$ collagenase (type 1A, Sigma, Zwijndrecht, Netherlands) in DMEM (with L-glutamine and gentamicin) for two hours at $37^{\circ} \mathrm{C}$. The cell suspension was filtered through a cell strainer $(70 \mu \mathrm{m})$ (Beckton Dickinson, Franklin Lakes, New Jersey, USA) and washed with phosphate buffered saline. Cells were cultured in a $5 \% \mathrm{CO}_{2} / 37^{\circ} \mathrm{C}$ incubator in DMEM with 10\% FCS, and non-adherent cells were discarded after overnight incubation. At passage 3, the cell population consisted of CDI4 negative/5B5 positive cells (fibroblast-like synoviocytes) and these cells were used for experiments until passage 8 .

For all experiments the cells were plated in 6-well or 48well plates and serum starved for 24 hours in DMEM+1\% FCS to synchronise cells in a non-activating and non-proliferating phase. Next they were pretreated with increasing concentrations $(0.001 \mu \mathrm{M}$ to $10 \mu \mathrm{M}$ ) of RWJ 67657 (stock solution 10 $\mathrm{mM}$ in DMSO) for one hour before stimulation with $1 \mathrm{ng} / \mathrm{ml}$ IL- $1 \beta$ and/or TNF $\alpha$.

\section{Determination of MMP-1, MMP-3, TIMP-1, IL-6, and IL-8 levels in cell culture supernatants}

Confluent synovial fibroblasts $(\mathrm{n}=5)$ were plated in 48-well plates (10 000 cells $/ \mathrm{ml}$ per well) and treated as above. After 48 hours' stimulation, supernatants were harvested and concentrations of MMP-1, MMP-3, TIMP-1, IL- $6,{ }^{17}$ and IL- $8{ }^{18}$ were determined using enzyme linked immunosorbent assays (ELISAs) developed in our laboratory.

The MMP-3 ELISA has been described previously. ${ }^{19}$ Briefly, 96-well plates (Greiner M129A) were precoated with $\mathrm{F}(\mathrm{ab})_{2}$ fragments of goat anti-mouse IgG-Fc (Jackson, West Grove, Pennsylvania, USA) in 0.1 M carbonate buffer ( $\mathrm{pH} 9.6)$ for at least 48 hours. Plates were subsequently coated with monoclonal antibody anti-MMP-3 (clone 10D6, R\&D systems) for one hour at $37^{\circ} \mathrm{C}$. After sample incubation, bound MMP-3 was detected with rabbit anti-human MMP-3 (Ab 810, Chemicon, Temecula, California, USA), and $\mathrm{F}(\mathrm{ab})_{2}$ goat anti-rabbit IgG labelled with peroxidase (Zymed, San Francisco, California, USA). The colour reaction was achieved with tetramethylbenzidine (TMB) (Roth, Karlsruhe, Germany).

For the MMP-1 ELISA we used monoclonal anti-MMP-1 (clone 36665.111) and biotinylated goat anti-human MMP-1 (both from R\&D Systems). The TIMP-1 antibodies (R\&D Systems) in the ELISA were monoclonal anti-TIMP-1 (clone 63515.111) and biotinylated goat anti-human TIMP-1. The detection of the biotinylated antibodies was done with streptavidin-poly-HRP (CLB, Netherlands) and TMB colour reaction.

\section{RNA isolation}

Synovial fibroblasts $(\mathrm{n}=6)$ were plated in 6-well plates $\left(0.5 \times 10^{6}\right.$ cells $/$ well $\left./ 4 \mathrm{ml}\right)$ and treated as above. After six or 24 hours of stimulation, total RNA was isolated from the cells with Trizol reagent according to the manufacturer's instructions (Life Technologies). After DNase treatment (DNA-free, Ambion, Austin, Texas, USA) cDNA was synthesised from $2.0 \mu \mathrm{g}$ of total RNA using M-MLV reverse transcriptase and oligo $(\mathrm{dT})_{24}$.

\section{Real time RT-PCR}

For quantitative detection of mRNA expression a fluorescence based real time RT-PCR was undertaken, which allows relative quantification of steady state mRNA. The amount of emitted fluorescence is proportional to the amount of PCR product and enables monitoring of the PCR reaction. ${ }^{20}$ For the measurement of MMP-1, MMP-3, TIMP-1, ADAMTS-4, IL-6, IL-8, COX-2, and glyceraldehyde-3-phosphate dehydrogenase (GAPDH), $1 \mu \mathrm{l}$ of cDNA in duplicate was used for amplification by the real time quantitative PCR system (ABI Prism
7900HT Sequence Detection System, Applied Biosystems) with specific Taqman primers/probes.

The amount of target, normalised to an endogenous reference and relative to a calibrator, is given by: $2^{-\Delta \Delta \mathrm{CT}}$, in which CT is the threshold cycle. The results are expressed as -fold induction relative to untreated samples.

\section{Western blotting to detect phosphorylation of p38 MAPK and MAPKAPK-2}

Phosphorylation of p38 MAPK was analysed by western blotting. Synovial fibroblasts were plated in 6-well plates $\left(0.5 \times 10^{6}\right.$ cells $/$ well $\left./ 4 \mathrm{ml}\right)$ and treated as above. After stimulation with TNF $\alpha$ and/or IL-1 $\beta$ for up to 60 minutes, cell extracts were prepared by lysing the cells with $1 \times$ SDS sample buffer (containing 2\% SDS, 10\% glycerol, $50 \mathrm{mM}$ dithiothreitol, $62.5 \mathrm{mM}$ Tris- $\mathrm{HCl}(\mathrm{pH}=6.8)$, and $0.01 \%$ bromophenol blue). Cells were scraped off the wells and the lysates were subsequently sonicated for 5-10 seconds and boiled for five minutes. After centrifugation the samples were loaded onto a $10 \%$ SDS-PAGE gel and resolved by running at $200 \mathrm{~V}$ and $15 \mathrm{~W}$ constant. Semidry blotting onto a nitrocellulose membrane was followed by immunoblotting with specific antibodies to p38 MAPK, phospho-p38 MAPK, and phospho-MAPKAPK-2. Enhanced chemiluminescence (ECL) detection was done according to the manufacturer's guidelines (Lumi-Light ${ }^{\text {plus, }}$ Roche Diagnostics, Mannheim, Germany).

Effects of RWJ 67657 on phosphorylation of p38 MAPK and its downstream substrate MAPKAPK-2 were measured after incubation of the cells with the p38 MAPK inhibitor and stimulation with TNF $\alpha$ and/or IL-1 $\beta$ for 30 minutes.

\section{Statistics}

One way analysis of variance with Dunnett's post test or Bonferroni's multiple comparison test was employed using GraphPad Prism version 3.00 for Windows, GraphPad Software (San Diego, California, USA).

\section{RESULTS}

Effect of RWJ-67657 on protein production by rheumatoid synovial fibroblasts

Figure 1 shows the results of the production of MMP-1, MMP-3, TIMP-1, IL-6, and IL-8 by RSF $(n=5)$ after stimulation with TNF $\alpha$ and/or IL- $1 \beta$, and also after pretreatment with RWJ 67657. Production of MMP-3 after stimulation with IL-1 $\beta$ without RWJ 67657 led to higher production than stimulation with TNF $\alpha$ (15.0-fold), and the same was true to a lesser extent for MMP-1 (1.2-fold). TIMP-1 production was not induced when stimulated with either cytokine. Stimulation with both cytokines had a synergistic effect on MMP-3 production: 22.7-fold compared to TNF $\alpha$ alone and 1.6-fold compared to IL- $1 \beta$ alone. Preincubation with RWJ 67657 resulted in a significant dose dependent decrease in MMP-3 production when cells were stimulated with IL-1 $\beta$ alone or together with TNF $\alpha$. Only a high concentration $(10 \mu \mathrm{M})$ of the p38 MAPK inhibitor had an effect on MMP-1 production, while for TIMP-1 there was no effect of p38 MAPK treatment.

Stimulation with IL- $1 \beta$ led to higher productions of IL-6 and IL- 8 than stimulation with TNF $\alpha$ : 24.0 -fold for IL- 6 and 14.3-fold for IL-8. A dose dependent decrease in IL-6 and IL-8 production was seen after pretreatment with RWJ 67657.

We calculated the average percentage inhibition caused by treatment with RWJ 67657. More than 50\% inhibition of MMP-3 and IL-8 production could be achieved at $1 \mu \mathrm{M}$, more than $50 \%$ inhibition of MMP-1 at $10 \mu \mathrm{M}$, and more than $50 \%$ inhibition of IL-6 production at $0.1 \mu \mathrm{M}$. Control experiments were done by adding $0.1 \%$ DMSO (at a concentration of $10 \mu \mathrm{M}$ RWJ 67657) to stimulated RSF ( $\mathrm{n}=3$ ). No significant 


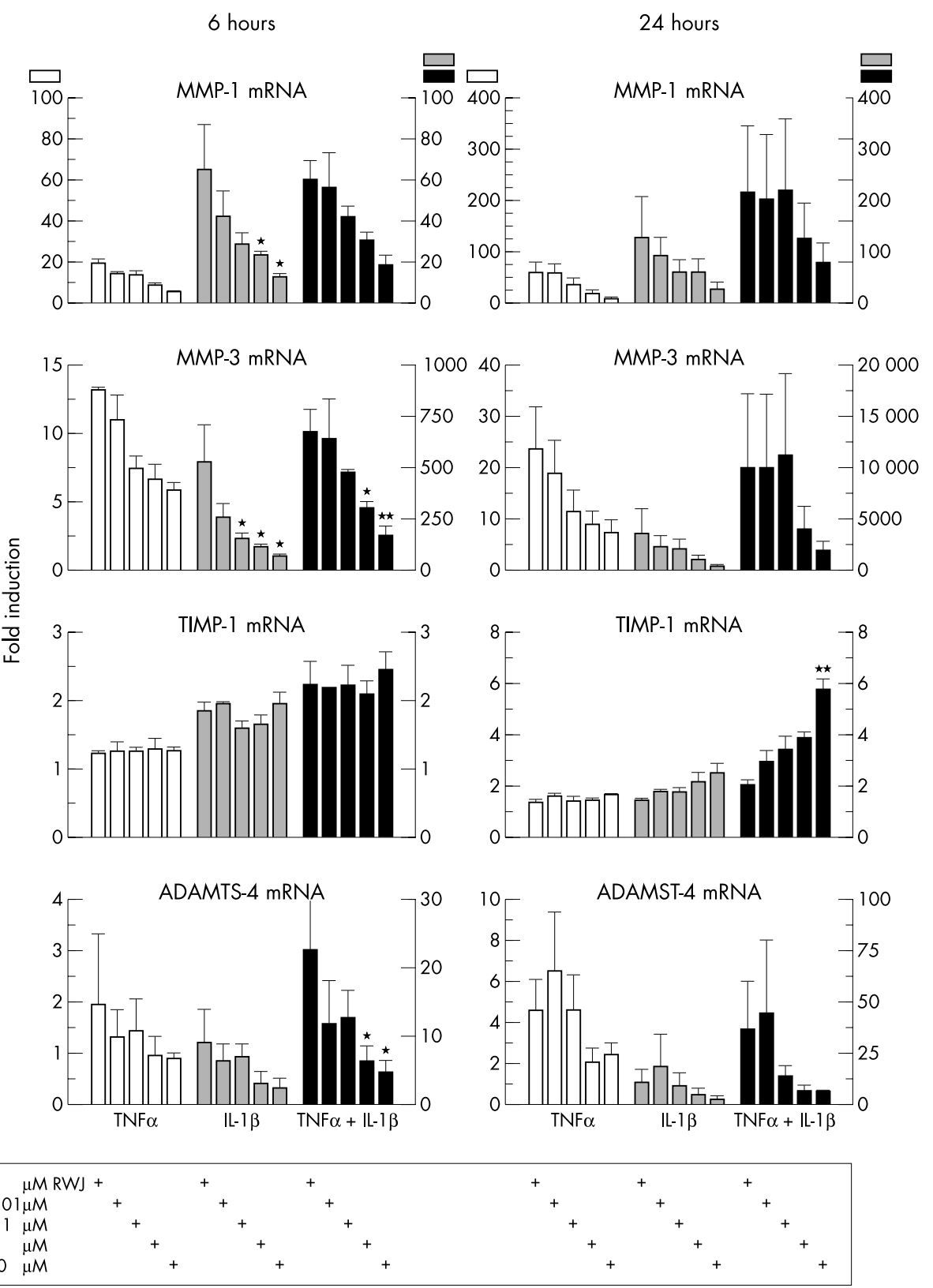

Figure 2 mRNA expression of MMP-1, MMP-3, TIMP-1, and ADAMTS-4 in rheumatoid synovial fibroblasts $(n=3)$. Cells were stimulated with TNF $\alpha$ and/or IL-1 $\beta$ for six and 24 hours and pretreated with a concentration range of RWJ 67657. mRNA expression was determined with real time RT-PCR (reverse transcriptase polymerase chain reaction) and results were expressed as -fold induction compared with unstimulated cells (fold induction $=1$ ). White bars represent values after TNF $\alpha$ stimulation (scale on left vertical axis); grey bars represent values after IL-1 $\beta$ stimulation and black bars after IL$1 \beta+T N F \alpha$ stimulation (scale on right vertical axis). Bars represent means and SEM. ${ }^{*} p<0.05$, Bonferroni multiple comparison test, tested against the stimulated control. ADAMTS, a disintegrin and metalloprotease with thrombospondin-1 motif; MMP, matrix-metalloproteinase; TIMP-1, tissue inhibitor of matrix-metalloproteinases.

inhibition of protein production could be detected as a result of the DMSO (data not shown).

\section{Effect of RWJ 67657 on mRNA expression}

A time course study after stimulation with TNF $\alpha$ and/or IL- $1 \beta$ was carried out to determine the time required for optimal mRNA expression. MMP-1 and MMP-3 mRNA expression was maximal after 24 hours, while IL-6, IL-8, and COX-2 mRNA had already reached maximum expression after six hours (data not shown).

Figure 2 shows the mean levels (expressed as -fold induction compared with untreated cells $=1$ ) for MMP-1, MMP-3, TIMP-1, and ADAMTS-4 mRNA expression of three different RSF after six and 24 hours of stimulation and after pretreatment with RWJ 67657. As with protein production, mRNA expression of MMP-3 was much greater after stimulation with IL-1 $\beta$ than after stimulation with TNF $\alpha$ : 40.1-fold after six hours of stimulation, and up to 149.4-fold after 24 hours. The equivalent values for MMP-1 mRNA expression were 3.4-fold after six hours and 2.1-fold after 24 hours, although the absolute expression increased with time. TIMP-1 mRNA expression hardly increased after stimulation (maximum two- to threefold compared with unstimulated cells). ADAMTS-4 mRNA expression could be measured in synovial fibroblasts and increased with time. Again the expression after IL- $1 \beta$ stimulation was greater than after 

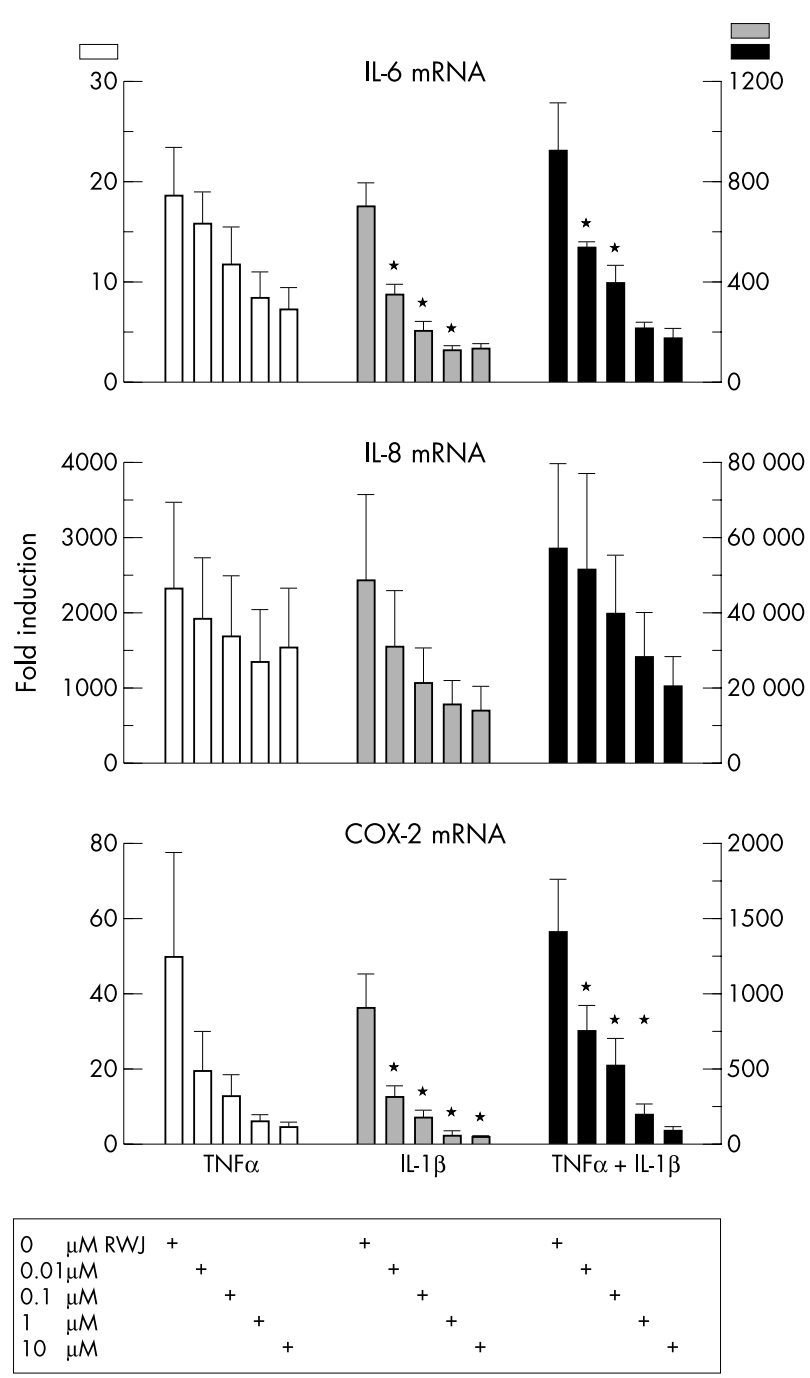

Figure 3 mRNA expression of IL-6, IL-8, and COX-2 in rheumatoid synovial fibroblasts $(n=3)$. Cells were stimulated with TNF $\alpha$ and/or IL-1 $\beta$ for six hours and pretreated with a concentration range of RWJ 67657. mRNA expression was determined with real time RT-PCR (reverse transcriptase polymerase chain reaction) and results are expressed as -fold induction compared with unstimulated cells (-fold induction $=1$ ). White bars represent values after TNF $\alpha$ stimulation (scale on left vertical axis); grey bars represent values after IL-1 $\beta$ stimulation and black bars after IL-1 $\beta+$ TNF $\alpha$ stimulation (scale on right vertical axis). Bars represent means and SEM. ${ }^{*} p<0.05$, Bonferroni multiple comparison test, tested against the stimulated control. COX, cyclo-oxygenase; IL, interleukin; TNF, tumour necrosis factor.

TNF $\alpha$ stimulation (4.7-fold after six hours, 2.3-fold after 24 hours).

Inhibition by RWJ 67657 could be detected for MMP-1 mRNA, MMP-3 mRNA, and ADAMTS-4 mRNA at both time points and after treatment with all stimuli. However, significant inhibition was seen for MMP-1 mRNA expression after six hours of IL- $1 \beta$ stimulation at $1 \mu \mathrm{M}$ RWJ 67657 and more. Significant inhibition of MMP-3 mRNA expression also occurred after six hours of IL-1 $\beta$ stimulation at $0.1 \mu \mathrm{M}$ and more, and with both stimuli at $1 \mu \mathrm{M}$ and more. TIMP-1 mRNA expression increased after 24 hours of stimulation with increasing concentrations of RWJ 67657. This effect was significant at $10 \mu \mathrm{M}$. ADAMTS-4 mRNA expression was significantly inhibited after six hours of stimulation with both cytokines at $1 \mu \mathrm{M}$ RWJ 67657 and more.

Figure 3 shows mRNA levels, expressed as -fold induction compared with unstimulated cells $(-$ fold induction $=1$ ) for
IL-6, IL-8, and COX-2 after stimulation for six hours and after treatment of three different rheumatoid synovial fibroblasts with different concentrations of RWJ 67657. Again there was a difference in expression after stimulation with TNF $\alpha$ or IL$1 \beta$. For IL-6, IL-8, and COX-2, respectively, stimulation with IL- $1 \beta$ gave 38.0-fold, 21.1 -fold, and 18.3-fold higher expression than after stimulation with TNF $\alpha$.

Significant inhibition of IL-6 mRNA expression was already seen at $0.01 \mu \mathrm{M}$ RWJ 67657 when RSF were stimulated with IL-1 $\beta$ alone or together with TNF $\alpha$. Inhibition of IL-8 mRNA expression was not significant, possibly because of a large interindividual response in IL-8 expression. COX-2 mRNA expression was significantly inhibited at $0.01 \mu \mathrm{M}$ RWJ 67657 when the cells were stimulated with IL- $1 \beta$ or the IL- $1 \beta+\mathrm{TNF} \alpha$ combination.

To determine whether RWJ 67657 also affected cells that were already stimulated, $0.01 \mu \mathrm{M}$ and $1 \mu \mathrm{M}$ of p38 MAPK inhibitor were added before and one hour after TNF $\alpha+$ IL-1 $\beta$ stimulation of two RSF cultures, and IL-6 and COX-2 mRNA expression was analysed. One hour after stimulation, phosphorylation of p38 MAPK had already reached maximum. When RWJ 67657 was added one hour before stimulation, the decrease in mRNA expression with RWJ 67657 concentrations of $0.01 \mu \mathrm{M}$ and $1 \mu \mathrm{M}$ was $59.8 \%$ and $97.9 \%$, respectively, for COX-2, and $38.4 \%$ and $71.5 \%$ for IL-6. When RWJ 67657 was added one hour after stimulation these values were $57.1 \%$ and $95.4 \%$ for COX-2 and $45.2 \%$ and $81.0 \%$ for IL-6. This shows that the p38 MAPK inhibitor also inhibited inflammatory mediator production in previously activated rheumatoid synovial cells.

Control experiments were carried out by adding $0.1 \%$ DMSO to stimulated RSF (RWJ 67657 concentration $10 \mu \mathrm{M}$ ). Significant reduction by $0.1 \%$ DMSO was seen only after IL-1 $\beta$ induced IL-6 mRNA expression and TNF $\alpha+$ IL-1 $\beta$ induced COX-2 mRNA expression. However, in both cases a significant reduction in mRNA expression was already found with $0.01 \mu \mathrm{M}$ RWJ 67657 at non-inhibiting DMSO concentrations.

\section{Effect of RWJ 67657 on phosphorylation}

First we investigated the phosphorylation rate of p38 MAPK after stimulation with TNF $\alpha$ and/or IL- $1 \beta$ in rheumatoid synovial fibroblasts. As shown in fig 4A, phosphorylation occurred rapidly and started after five minutes, reaching its maximum at 15 to 30 minutes for both stimuli. As expected, no inhibition of phosphorylation of p38 MAPK by RWJ 67657 was found (fig 4B). For MAPKAPK-2, which is a direct downstream substrate of p38 MAPK, a strong inhibition of phosphorylation was demonstrated at concentrations down to $0.1 \mu \mathrm{M}$ RWJ 67657 .

\section{DISCUSSION}

In this study we showed significant inhibition by the p38 MAPK inhibitor RWJ 67657 of proinflammatory mediator and protease production in rheumatoid synovial fibroblasts. When inhibition was seen at the protein level, there was also inhibition at the level of mRNA expression, which means that this inhibition is at least at the level of RNA transcription.

TNF $\alpha$ and IL-1 are considered the most important cytokines in the process of inflammation in rheumatoid arthritis. Studies in experimental models have shown that $\mathrm{TNF} \alpha$ is indeed a pivotal cytokine in acute joint swelling, whereas IL- $1 \beta$ is the dominant cartilage destroying cytokine. $^{21}$ Therefore we used both cytokines for activation of synovial fibroblasts to investigate the effects of a p38 MAPK inhibitor.

Stimulation of RSF with IL-1 $\beta$ or TNF $\alpha$ had different effects. Production of MMP-3 was greater after stimulation with IL- $1 \beta$ than with $\mathrm{TNF} \alpha$, although there was a synergistic 


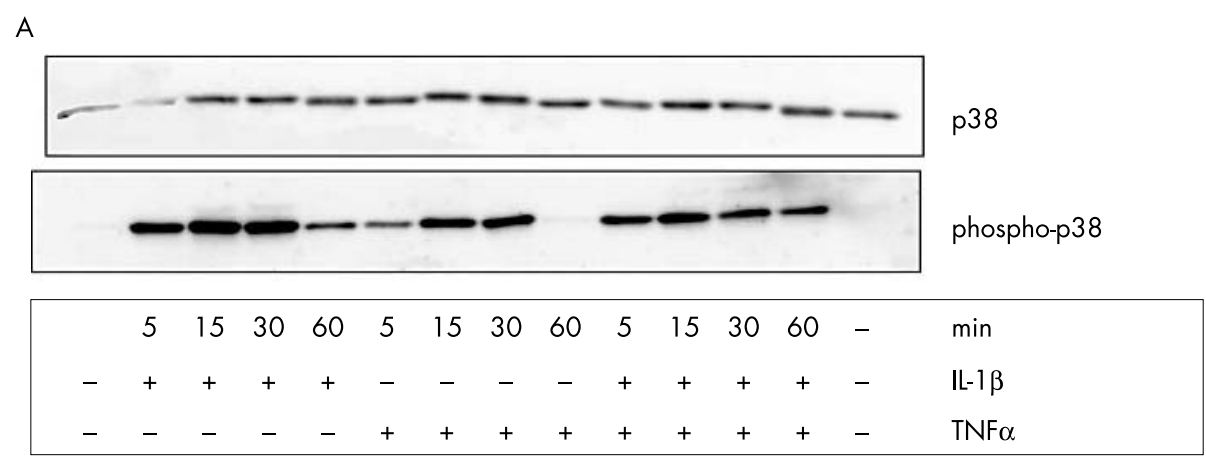

B

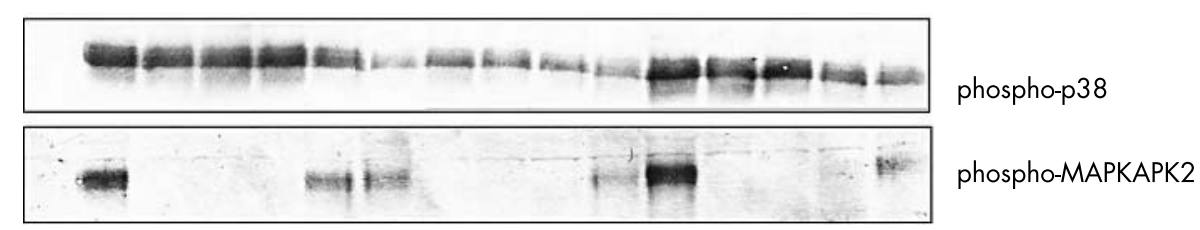

\begin{tabular}{|c|c|c|c|c|c|c|c|c|c|c|c|c|c|c|c|}
\hline - & + & + & + & + & + & - & - & - & - & - & + & + & + & $+\quad+$ & IL-1 $\beta$ \\
\hline+ & + & + & + & + & + & + & + & + & + & + & + & + & + & $+\quad+$ & $\mathrm{TNF} \alpha$ \\
\hline _ & _ & 10 & 1 & 0.1 & 0.01 & - & 10 & 1 & 0.10. & 0.01 & _- & 10 & 1 & 0.10 .01 & $\mu M R W J$ \\
\hline
\end{tabular}

Figure 4 (A) Representative presentation of phosphorylation of p38 MAPK in rheumatoid synovial fibroblasts after stimulation with TNF $\alpha$ and/or IL$1 \beta$ at different time points. (B) Phosphorylation was measured by Western blot using specific antibodies. Effect of RWJ 67657 on phosphorylation of the direct substrate of p38 MAPK, MAPKAPK-2, measured after 30 minutes of stimulation. IL, interleukin; MAPK, mitogen activated protein kinase; TNF, tumour necrosis factor.

effect. Significant inhibition of induced production was seen when the cells were pretreated with $1 \mu \mathrm{M}$ of the p38 MAPK inhibitor. MMP-1 protein production could be induced after stimulation (five- to sevenfold), but relevant inhibition was seen only at a concentration of $10 \mu \mathrm{M}$ of RWJ 67657, which is too high for use in humans. A study by Parasrampuria et $a l^{16}$ showed that a single oral dose of 0.25 to $30 \mathrm{mg} / \mathrm{kg}$ resulted in plasma concentrations of RWJ 67657 between $0.01 \mu \mathrm{M}$ and $6 \mu \mathrm{M}$. No up- or downregulation was seen for TIMP-1 production after stimulation and treatment with RWJ. TIMP-1 is constitutively expressed, and the expression is not influenced by TNF $\alpha$ or IL- $1 \beta$, and consequently not by p38 MAPK inhibition either.

With quantitative real time RT-PCR we measured mRNA levels of MMP-1, MMP-3, TIMP-1, and ADAMTS-4. IL-1 $\beta$ induced higher levels of mRNA expression for MMP-1, MMP-3, and ADAMTS-4 than TNF $\alpha$. Moreover, we showed inhibition of mRNA expression for these genes by the p38 MAPK inhibitor. Others have found that activation of $\mathrm{p} 38$ MAPK in human skin fibroblasts enhances MMP-1 and MMP-3 expression by mRNA stabilisation. ${ }^{22}$ This is in agreement with our findings, indicating that inhibiting the p38 MAPK signal transduction route in RSF decreased expression of MMP-3 mRNA and to a lesser extent of MMP-1 mRNA. Work from our group has established the importance of MMP-3 as an indicator of radiological progression in early rheumatoid arthritis, especially of joint space narrowing, which represents cartilage degradation. ${ }^{23}$ As others have shown that both aggrecanases and matrixmetalloproteinases degrade cartilage in human joints, ${ }^{24}{ }^{25}$ the inhibition by RWJ 67657 could be important in the treatment of rheumatoid arthritis.

The expression of TIMP-1 mRNA was only affected after 24 hours of stimulation with increasing concentrations of RWJ
67657, which could have a protective effect by neutralising MMPs. As GAPDH levels were constant, possible adverse effects of RWJ 67657 did not induce this phenomenon.

IL-6 and IL-8 are important cytokines in inflammation and both are present at high concentrations in synovial fluids of patients with rheumatoid arthritis. ${ }^{17}$ Strong induction of both cytokines in RSF could be demonstrated after IL- $1 \beta$ stimulation particularly. RWJ 67657 significantly inhibited this induced IL-6 and IL-8 production at $0.01 \mu \mathrm{M}$ and $0.1 \mu \mathrm{M}$. Suzuki et $a l^{5}$ reported the decrease in IL-6 and IL-8 protein production after treatment with SB 203580, but no effect on mRNA expression, measured by traditional RT-PCR at a concentration of $30 \mu \mathrm{M}$. With quantitative real time RT-PCR we detected inhibition of both IL-6 and IL-8 mRNA expression. Therefore this study showed that IL-6 and IL-8 are inhibited by RWJ 67657 both at the protein and the mRNA level.

In 1998 Guan et al reported that the induction of COX-2 and production of $\mathrm{PGE}_{2}$ were directly linked to activation of MEKKl and consequently to activation of p38 MAPK. ${ }^{26}$ Recently it was reported that COX-2 mRNA stability is under regulation by p38 MAPK. ${ }^{10}{ }^{27}$ In our study we demonstrated upregulation of COX-2 mRNA after stimulation with IL- $1 \beta$ or $\mathrm{TNF} \alpha$, and very strong inhibition by RWJ 675657, especially after IL- $1 \beta$ induced expression. Effects of p38 MAP inhibition are partly mediated through its downstream kinase MAPKAPK-2 and may involve phosphorylation of hsp27. ${ }^{28}$ Our results showed that after 30 minutes p38 MAPK was already maximally phosphorylated and that MAPKAPK-2 phosphorylation was blocked at a concentration of $0.1 \mu \mathrm{M}$. Addition of RWJ 67657 to stimulated cells did not affect the inhibitory capacities of the compound, so inhibition of the p38 MAPK signal transduction route in activated cells is possible. 
p38 MAPK inhibitors have very potent effects on TNF $\alpha$ production by LPS stimulated monocytes at low concentration. For RWJ 67657 this was established at $3 \mathrm{nM} .{ }^{14}$ For monocyte derived macrophages, $50 \%$ inhibition was reached at a concentration of $30 \mathrm{nM} .^{29}$ Our study here clearly showed that IL- $1 \beta$ is a stronger inducer of expression of inflammatory mediators by synovial fibroblasts than TNF $\alpha$ and may as such be the major cartilage destructive cytokine. p38 MAPK inhibitors such as RWJ 67657 inhibit both IL-1 $\beta$ and TNF $\alpha$, as well as the responses induced by these cytokines. This dual activity of p38 MAPK inhibitors may be of major importance in the treatment of rheumatoid arthritis and other inflammatory conditions.

p38 MAPK inhibitors have effects on different cell types, which could enhance the therapeutic effects but also increase the risk of side effects. In the past, clinical trials with other p38 MAPK inhibitors have been stopped because of safety issues. One of the reasons for undesirable effects might be cross reactivity against other kinases, which was not the case for RWJ 67657. Furthermore we excluded induction of apoptosis in RSF following incubation with RWJ 67657 by staining cells with Annexin V and propidium iodide as described previously ${ }^{30}$ (data not shown). However, RWJ 67657 has been found to have acceptable safety and pharmacokinetic characteristics, warranting further investigation. ${ }^{16}$ There were no adverse effects associated with single doses of this drug. While the preliminary pharmacokinetic data suggest a twice daily dosing regimen, our data show significant effects at low concentrations. More research upon the effects of p38 MAPK inhibition on other cell types involved in inflammation will establish its applicability as a drug in the near future. The results presented in this study are promising.

\section{Authors' affiliations}

J Westra, P C Limburg, M H van Rijswijk, Department of Rheumatology, University Hospital Groningen, Groningen, Netherlands

P C Limburg, Pathology and Laboratory Medicine, University Hospital Groningen

P de Boer, Pharmaceutical Research and Development, Johnson and Johnson, Saunderton, Buckinghamshire, UK

We gratefully acknowledge Dr Fred Breukelman and Dr Lex Boerboom for delivery of the synovial tissues. We thank Dr Marco Harmsen and Dr Sigga Asgeirsdottir for assistance with the PCR experiments and Dr Miek van Leeuwen for critically reading of the manuscript. We are grateful to Mrs Berber Doornbos-van der Meer for her excellent technical assistance. The work was supported by the Dutch Rheumatology Foundation and Johnson and Johnson Pharmaceutical Research and Development, Raritan, New Jersey, USA.

\section{REFERENCES}

1 Pap T, Muller-Ladner U, Gay RE, Gay S. Fibroblast biology. Role of synovial fibroblasts in the pathogenesis of rheumatoid arthritis. Arthritis Res 2000;2:361-7.

2 Firestein GS, Manning AM. Signal transduction and transcription factors in rheumatic disease. Arthritis Rheum 1999;42:609-21

3 Cobb MH, Goldsmith EJ. How MAP kinases are regulated. J Biol Chem 1995:270:14843-6.

4 Dong C, Davis RJ, Flavell RA. MAP kinases in the immune response. Annu Rev Immunol 2002;20:55-72.

5 Suzuki M, Tetsuka T, Yoshida S, Watanabe N, Kobayashi M, Matsui N, et al. The role of $\mathrm{p} 38$ mitogen-activated protein kinase in IL-6 and IL-8 production from the TNF-alpha- or IL1 beta-stimulated rheumatoid synovial fibroblasts. FEBS Lett 2000;465:23-7.

6 Ridley SH, Sarsfield SJ, Lee JC, Bigg HF, Cawston TE, Taylor DJ, et al. Actions of IL-1 are selectively controlled by p38 mitogen-activated protein kinase: regulation of prostaglandin $\mathrm{H}$ synthase-2, metalloproteinases, and IL-6 at different levels. J Immunol 1997;158:3165-73.
7 Ravanti L, Hakkinen L, Larjava H, Saarialho-Kere U, Foschi M, Han J, et al. Transforming growth factor-beta induces collagenase- 3 expression by human gingival fibroblasts via p38 mitogen-activated protein kinase. J Biol Chem 1999:274:37292-300.

8 Yamanishi Y, Boyle DL, Clark M, Maki RA, Tortorella MD, Arner EC, et al. Expression and regulation of aggrecanase in arthritis: the role of TGF- beta. $J$ Immunol 2002;168:1405-12.

9 Guan Z, Baier LD, Morrison AR. p38 mitogen-activated protein kinase downregulates nitric oxide and up-regulates prostaglandin E2 biosynthesis stimulated by interleukin-1 beta. J Biol Chem 1997;272:8083-9.

10 Lasa M, Brook M, Saklatvala J, Clark AR. Dexamethasone destabilizes cyclooxygenase 2 mRNA by inhibiting mitogen-activated protein kinase p38. Mol Cell Biol 2001;21:771-80.

11 Badger AM, Cook MN, Lark MW, Newman-Tarr TM, Swift BA, Nelson AH et al. SB 203580 inhibits p38 mitogen-activated protein kinase, nitric oxide production, and inducible nitric oxide synthase in bovine cartilage-derived chondrocytes. J Immunol 1998;161:467-73.

12 Branger J, van den BB, Weijer S, Madwed J, Bos CL, Gupta A, et al. Antiinflammatory effects of a p38 mitogen-activated protein kinase inhibitor during human endotoxemia. J Immunol 2002;168:4070-7.

13 Haddad JJ. VX-745. Vertex Pharmaceuticals. Curr Opin Investig Drugs 2001;2:1070-6.

14 Wadsworth SA, Cavender DE, Beers SA, Lalan P, Schafer PH, Malloy EA, et al. RWJ 67657, a potent, orally active inhibitor of p38 mitogen-activated protein kinase. J Pharmacol Exp Ther 1999;291:680-7.

15 Fijen JW, Ziilstra JG, de Boer P, Spanjersberg R, Cohen Tervaert JW, van der Werf TS, et al. Suppression of the clinical and cytokine response to endotoxin by RWJ-67657, a p38 mitogen-activated protein-kinase inhibitor, in healthy human volunteers. Clin Exp Immunol 2001;124:16-20.

16 Parasrampuria DA, de Boer P, Desai-Krieger D, Chow AT, Jones CR. Singledose pharmacokinetics and pharmacodynamics of RWJ 67657, a specific p38 mitogen-activated protein kinase inhibitor: a first-in-human study. J Clin Pharmacol 2003;43:406-13

17 van Leeuwen MA, Westra J, Limburg PC, van Riel PL, van Rijswijk MH. Interleukin-6 in relation to other proinflammatory cytokines, chemotactic activity and neutrophil activation in rheumatoid synovial fluid. Ann Rheum Dis 1995;54:33-8

18 de Bont ES, Vellenga E, Swaanenburg JC, Fidler V, Visser-van Brummen PJ, Kamps WA. Plasma IL-8 and IL-6 levels can be used to define a group with low risk of septicaemia among cancer patients with fever and neutropenia. Br J Haematol 1999; 107:375-80.

19 Posthumus MD, Limburg PC, Westra J, van Leeuwen MA, van Rijswijk MH. Serum matrix metalloproteinase 3 levels during treatment with sulfasalazine or combination of methotrexate and sulfasalazine in patients with early rheumatoid arthritis. J Rheumatol 2002;29:883-9.

20 Klein D. Quantification using real-time PCR technology: applications and limitations. Trends Mol Med 2002;8:257-60.

21 van den Berg WB, Bresnihan B. Pathogenesis of joint damage in rheumatoid arthritis: evidence of a dominant role for interleukin-I. Baillieres Best Pract Res Clin Rheumatol 1999;13:577-97.

22 Reunanen N, Li SP, Ahonen M, Foschi M, Han J, Kahari VM. Activation of p38 alpha MAPK enhances collagenase-1 (matrix metalloproteinase (MMP)1) and stromelysin-1 (MMP-3) expression by mRNA stabilization. J Biol Chem 2002;277:32360-8

23 Posthumus MD, Limburg PC, Westra J, van Leeuwen MA, van Rijswijk MH. Serum matrix metalloproteinase 3 in early rheumatoid arthritis is correlated with disease activity and radiological progression. J Rheumatol 2000;27:2761-8

24 Lark MW, Bayne EK, Flanagan J, Harper CF, Hoerrner LA, Hutchinson NI, et al. Aggrecan degradation in human cartilage. Evidence for both matrix metalloproteinase and aggrecanase activity in normal, osteoarthritic, and rheumatoid joints. J Clin Invest 1997; 100:93-106

25 Little CB, Flannery CR, Hughes CE, Mort JS, Roughley PJ, Dent C, et al. Aggrecanase versus matrix metalloproteinases in the catabolism of the interglobular domain of aggrecan in vitro. Biochem J 1999;344:61-8.

26 Guan Z, Buckman SY, Pentland AP, Templeton DJ, Morrison AR. Induction of cyclooxygenase- 2 by the activated $M E K K 1 \rightarrow$ SEK $1 /$ MKK $4 \rightarrow$ p38 mitogenactivated protein kinase pathway. J Biol Chem 1998;273:12901-8.

27 Faour WH, He Y, He QW, de Ladurantaye M, Quintero M, Mancini A, et al. Prostaglandin $\mathrm{E}(2)$ regulates the level and stability of cyclooxygenase-2 mRNA through activation of p38 mitogen-activated protein kinase in interleukin-1 beta-treated human synovial fibroblasts. J Biol Chem $2001 ; 276: 31720-31$.

28 Lasa M, Mahtani KR, Finch A, Brewer G, Saklatvala J, Clark AR. Regulation of cyclooxygenase 2 mRNA stability by the mitogen-activated protein kinase p38 signaling cascade. Mol Cell Biol 2000;20:4265-74.

29 Westra J, Doornbos-van der Meer B, de Boer P, van Leeuwen MA, van Rijswijk MH, Limburg PC. Strong inhibition of TNF $\alpha$ production and inhibition of IL-8 and COX-2 mRNA expression in monocyte derived macrophages by RWJ 67657, a p38 mitogen activated protein kinase (MAPK) inhibitor. Arthritis Res Ther 2004;6:384-92.

30 Bijl M, Horst G, Bïzet J, Bootsma H, Limburg PC, Kallenberg CG. Serum amyloid $\mathrm{P}$ component binds to late apoptotic cells and mediates their uptake by monocyte-derived macrophages. Arthritis Rheum 2003;48:248-54. 